\title{
Optimized Method to Analyze Rose Plant Volatile Organic Compounds by HS-SPME-GC-FID/MSD
}

\author{
Mohammed Ibrahim¹,2, Manjree Agarwal ${ }^{1}$, Giles Hardy' ${ }^{1}$, Yonglin Ren ${ }^{*}$ \\ ${ }^{1}$ School of Veterinary and Life Science, Murdoch University, Murdoch, Australia \\ ${ }^{2}$ College of Agriculture, University of Babylon, Babylon, Iraq \\ Email: *y.ren@murdoch.edu.au
}

How to cite this paper: Ibrahim, M., Agarwal, M., Hardy, G. and Ren, Y.L. (2017) Optimized Method to Analyze Rose Plant Volatile Organic Compounds by HSSPME-GC-FID/MSD. Journal of Biosciences and Medicines, 5, 13-31.

https://doi.org/10.4236/jbm.2017.53003

Received: February 21, 2017

Accepted: March 7, 2017

Published: March 10, 2017

\begin{abstract}
A method involving Headspace solid-phase microextraction (HS-SPME) fiber combined with gas chromatography (GC) coupled with flame ionization detection (FID) and gas chromatography with mass spectrometry (GC-MS) was developed and optimized to investigate volatile organic compounds (VOCs) from different tissues (flowers, leaves, stems, rhizosphere and whole plants) of Floribunda and Hybrid Tea roses (intact and cut). Three-phase fiber 50/30 $\mu \mathrm{m}$ divinylbenzene/carboxen/polydimethylsiloxane (DVB/CAR/PDMS) was used. Two types of chambers (Tedlar bag and glass jar) were evaluated for collection of VOCs and glass jar was selected. Absorbed compounds on the fiber were completely desorbed in the GC injector port at three desorption times $(5,10$ and $15 \mathrm{~min}$ ), and $5 \mathrm{~min}$ at $250^{\circ} \mathrm{C}$ was used. The maximum extraction efficiency for flowers tissues (equilibrium absorption) was achieved $2 \mathrm{~h}$ after fiber exposure in the headspace for intact and cut Floribunda and Hybrid Tea flowers. Under the optimized HS-SPME and GC-FID/MS conditions, $1 \mathrm{~h}$ extraction time was chosen for intact and cut Floribunda and Hybrid Tea leaves and stems. The results demonstrated that $5 \mathrm{~cm}$ depth was selected for root and soil part (rhizosphere) for both rose cultivars, and $6 \mathrm{~h}$ and $12 \mathrm{~h}$ extraction time of VOCs from rhizosphere was achieved for Floribunda and Hybrid Tea, respectively. One hour was chosen for VOCs released from whole rose plants for both cultivars. In this study, the VOC profiles of two rose cultivars were characterized by the optimized HS-SPME-GC method. The different tissues of rose plants gave wide range of the VOCs; also the chromatograms of different cultivars were quite different and the specific VOC pattern of rose types depends on the species. Results from this study demonstrate the feasibility of this method for identifying VOCs from two rose cultivars and the potential use of this method for physiological studies on rose plants or on other floriculture plants.
\end{abstract}




\section{Keywords}

Optimization, Rose tissues, VOCs, SPME-GC-FID/MS, Floribunda, Hybrid Tea

\section{Introduction}

Roses (Rosa hybrida L.) are an important ornamental plant of the family Rosacea. The genus Rosa includes about 100 - 200 species and more than 18,000 cultivars [1] [2]. The family Rosacea is recognized for its high economic value and use in agro-based industries, especially in cosmetics, perfumes, food and pharmaceutical industries [3] [4]. Roses are the most important cut flower crop in the world, with Australia exporting about 6,720,221 stems with an approximate value of $\$ 3,743,000$ in 2016 . In contrast, Australia imports about 204,001,778 stems at a cost of about $\$ 63,838,000$ in 2016 [5]. The main industrial application of roses comes from the perfume industry, which relies on different scented rose varieties [6] [7] [8] [9] [10]. Among these varieties are the Hybrid Tea rose and Floribunda rose cultivars, both of which are modern roses. The Hybrid Tea rose is a cross between European and Chinese roses [11] [12]. Floribunda is the result of crossing hybrid tea with Polyantha [13].

Roses emit a wide range of volatiles organic compounds (VOCs) from flowers, leaves, stem and roots [14]. These can be extracted by various techniques, such as hydro-distillation, microwave extraction, and solvents, all of these methods require grinding and adding solvents. Thus some chemicals which are released from the plants will not appear. In contrast, recently solid phase microextraction (SPME) was developed to capture VOCs which is used to profile and quantify these compounds. Most studies have focused on volatile emissions from flowers or fruits, with little is known about emissions from other plant tissues, such as leaves, stems, roots and even the whole plant including rhizosphere soil. There are many methods for obtaining rose volatiles, such as rose oil (essential oil) and these methods have been extensively reviewed [15] [9] [16] [17]. Unfortunately, the aroma of extracted oils rarely represents the delicate natural aroma of floriculture plants, because of thermal artefacts produced during the steam distillation process (which typically occurs at $60^{\circ} \mathrm{C}-70^{\circ} \mathrm{C}$ ) [18]. Likewise, other extraction methods using ground samples and solvents also frequently fail to capture the natural aromas [19] [20] [21]. Studies by [22] [23] indicated that essential oils extracted from Chrysanthemum did not fully represent the delicate natural aroma. To identify VOCs produced by roses or other plants, it is necessary to develop sensitive, non-destructive, rapid and systematic methods from different plant tissues that are also cost effective. There are no studies about the use of headspace solid phase microextraction HS-SPME for fresh intact or excised tissues obtained from roses. The SPME method is widely used for the analysis of volatile compounds, and it is successfully employed to monitor the extraction of aromatic components for Jasminum [24]. The HS-SPME technique is a new, 
simple, fast, and highly sensitive and solvent-free sample preparation technique for the extraction of volatile compounds [25] [26] [27].

The HS-SPME technique also provides interesting results when gas chromatography (GC) is combined with Flame Ionization Detector (FID) and mass spectrometric detection (MS). The SPME technique gives simultaneously tens or hundreds of possible volatile compounds, but it must be optimized for the volatiles being targeted [28] [29]. There are many factors that affect the optimization of extraction conditions. These include the correct fibre and an appropriate chamber for capturing the VOCs, the temperature used during extraction and the extraction time from the headspace [30]. In the past, optimization experiments have only analysed a variable at a time, this approach does not allow any investigation into the possible interactions between variables, and hence it is not possible to explore fully the opportunities for optimization [31]. To date, there has been no systematic work on optimizing extraction conditions for individual tissues of rose plants or the whole plant. Therefore, developing robust and practical methods for the extraction of VOCs from rose plants has important commercial implications for the aroma industry. The objective of the present work is the systematic optimization of HP-SPME methods, and analysis of VOCs from different rose tissues, and intact plants by gas chromatography coupled with Flame Ionization Detector and Mass Spectrometry (GC-FID/MS).

\section{Materials and Methods}

\subsection{Reagents}

Ethanol was purchased from MERK (high-performance liquid chromatography [HPLC] grade). An n-hexane 95\% was purchased from Sigma-Aldrich Australia, catalogue number 270504-2L, and the n-Alkane standard (C7-C30) was purchased from Sigma-Aldrich Australia, catalogue number 49451-U.

\subsection{Apparatus and Equipment}

An Agilent Technologies gas chromatograph 7829A (serial number CN14272038) fitted with a HP-5MS column non-polar ( $30 \mathrm{~m}$ x $0.25 \mathrm{~mm}$, film thickness 0.25 $\mu \mathrm{m}, \mathrm{RESTEK}$, catalogue number 13423), with a flame ionization detector (FID) was used throughout the study. Three replicate solid phase microextraction (SPME) fibres 50/30 $\mu \mathrm{m}$ divinylbenzene/ carboxen/polydimethyl siloxane (DVB/ CAR/PDMS; Sigma-Aldrich Australia, catalog number 57347-U), attached to a manual SPME holder (Supelco Inc.) were used. The fibres were conditioned as recommended by the manufacturer before analyses were conducted. In order to collect samples from the rhizosphere profile of rose plants, hollow sample probes $20 \mathrm{~cm}$ long were made from stainless steel, and one millimetre diameter holes were cross drilled at $5 \mathrm{~mm}$ increments from the tapered end up the probe to 3.5 $\mathrm{cm}$ from the top. A $1 / 8 \mathrm{~cm}$ compression fitting with a septum was installed into the top of the probe to facilitate insertion of the SPME fibre. A single tube was inserted into each pot to capture the VOCs. For whole plants, a glass chamber $(30 \times 35 \times 60 \mathrm{~cm})$ with a $5 \mathrm{~mm}$ port drilled into one side, into which a septum 
was placed to accommodate the SPME fibre and was designed for the extraction of VOCs (Table 1). For excited rose tissues, a $500 \mathrm{ml}$ Pyrex (Silverlock Packaging; JG2701 FL) glass jar with a $5 \mathrm{~mm}$ port drilled into one side, into which a septum was placed (Table 1). As a comparison to the glass jar, Tedlar bag about $0.5 \mathrm{~L}$ was purchased from SKC, Inc (catalogue number 236-001, $0.5 \mathrm{~L}$ from SKC). Aluminium foil $150 \mathrm{~m} \times 44 \mathrm{~cm}$ (Vital Packaging Company) was used to cover the glass chambers and jars top which VOCs were extracted and also used for extract VOCs from intact stems (Table 1).

\subsection{Plant Material and Maintenance}

This study was conducted on two-year-old rose plants (Hybrid Tea cv. Mr Lincoln) and (Floribunda cv. Iceberg), purchased from Dawson's Garden World nursery (Perth, Western Australia). These were immediately transferred to freedraining plastic pots $24 \times 24 \mathrm{~cm}$ in a 1:1 v:v (potting mix:soil) and placed into an evaporatively cooled glasshouse at Murdoch University. The temperature ranged between $18^{\circ} \mathrm{C} \pm 2^{\circ} \mathrm{C}$ to $25^{\circ} \mathrm{C} \pm 2^{\circ} \mathrm{C}$ during night and day, respectively with humidity $60 \% \pm 2 \%$ to $75 \% \pm 2 \%$ during night and day, respectively. The rose plants were watered manually daily to container capacity with about $400 \mathrm{ml}$ water. The rose pots were arranged in a factorial based complete randomize design with two rose types and five rose tissues and three replicates for each.

\subsection{Gas Chromatogram Condition Optimization}

The optimization step of the SPME conditions was necessary to identity the compounds by using the flame ionization detector (FID). The oven column temperature ranged from $50^{\circ} \mathrm{C}-250^{\circ} \mathrm{C}$, programmed at $5^{\circ} \mathrm{C} / \mathrm{min}$, with a final hold time of $5 \mathrm{~min}$. Helium $(\mathrm{He})$ was used as the carrier gas at $1.1 \mathrm{~mL} / \mathrm{min}$ constant flow, and FID temperatures of $290^{\circ} \mathrm{C}$, injection port temperature $250^{\circ} \mathrm{C}$, and the GC-FID instrument was operated under the splitless mode.

\subsection{Optimization of Headspace Solid-Phase Microextraction}

For optimization of the HS-SPME, the variables chosen were extraction time

Table 1. Different rose tissues and type of chambers which used to detect the VOCs from two types of rose in this study.

\begin{tabular}{ccccc}
\hline Rose tissue & Type & Chamber type & Measurements & Sample Amount \\
\hline \multirow{2}{*}{ Flowers } & Intact & Glass jar & $500 \mathrm{ml}$ & One flower \\
& Cut & Glass jar & $500 \mathrm{ml}$ & \\
Leaves & Intact & Glass jar & $500 \mathrm{ml}$ & Three leaflet \\
& Cut & Glass jar & $500 \mathrm{ml}$ & \\
Stems & Intact & Aluminium foil & $30 \times 30 \mathrm{~cm}$ & Length $13 \mathrm{~cm}$ \\
Root & Cut & Glass jar & $500 \mathrm{ml}$ & S cm depth \\
Whole plant & Intact & Sample probe & $3.5 \mathrm{~cm} \mathrm{drilled}$ & Whole plant \\
\hline
\end{tabular}


(min), desorption time (min), and the four types of chambers (glass chamber, glass jar, sample probe, and aluminium foil) for extraction, while the SPME fibre (DVB/CAR/PDMS), the fibre extraction temperature of $24^{\circ} \mathrm{C} \pm 1^{\circ} \mathrm{C}$, the amount of sample and the headspace volume were kept constant. Different extraction times, different desorption times and different extraction chambers were used for the different roses tissues. In order to optimize the adsorption time and extraction times, all factors influencing the equilibrium between the analyses and the fibre were taken into consideration. The fibres were cleaned between each extraction by placing them into the GC injection port for $15 \mathrm{~min}$ at $250^{\circ} \mathrm{C}$ to ensure absence of carry over peaks and contaminants in blanks to have good repeatability between the injections. The three replicate fibres were calibrated using standard n-alkene C7-C30 after dilution in the ratio of 1/10 ml in n-hexane, and then desorbed for one hour at room temperature and this procedure was repeated twice with three replicates before analysis. The results are presented as the mean values obtained.

\subsubsection{Optimisation of Sample Chambers}

To determine the most efficient extraction method of the VOCs emitted by intact and excised tissues of the rose plants, a comparison was made between the Tedlar bag and a Pyrex glass jar $(0.5 \mathrm{~L})$. The results showed that there were no differences between the Tedlar bag and glass jar, so the jar was chosen because it was easy to handle, readily captured the VOCs emitted. Individually, rose flowers, leaves or cut stems were placed into the Pyrex glass jar and the opening covered with aluminium foil and incubated at $25^{\circ} \mathrm{C}$ for 1,2 and $3 \mathrm{~h}$, respectively. Aluminium foil was used for intact stems. Whilst for the analysis of VOCs from the whole plant including the soil, a glass chamber $(30 \times 35 \times 60 \mathrm{~cm})$ was used. For the capture of VOCs from the roots and soil, single stainless steel was insertion into the soil.

\subsubsection{Optimisation of Sealing and Fibre Absorption and Desorption Time}

The determine the best absorption time; the fibres were exposed to the headspace of the different chambers with each of the plant tissues for either 1, 2 and 3 h. After exposure, the fibre was retrieved and injected into the heated GC injection port $\left(250^{\circ} \mathrm{C}\right)$ for desorption. For each chamber type, plant tissue type and time combination, there were three replicate samples. To optimize the GC injector desorption time, three different desorption time (5, 10 and $15 \mathrm{~min}$ ) were used at $250^{\circ} \mathrm{C}$.

\subsection{Optimization of Collection of VOCs from Different Tissues of Rose Plants}

The rose tissues studied were intact or excised flowers, stems, or leaves and whole plants including the roots in soil. Each was replicated three times.

Briefly, rose plants were transferred to the laboratory and either an excised or intact single fully open flower, leaves (three fully expanded and undamaged 
leaves), or stem $(13 \mathrm{~cm})$ was inserted into the $500 \mathrm{ml}$ glass jar at room temperature $\left(25^{\circ} \mathrm{C} \pm 2{ }^{\circ} \mathrm{C}\right)$. The jar was covered with aluminium foil and then the SPME fibre was immediately inserted into the headspace for 1,2 or $3 \mathrm{~h}$. For the roots, the rhizosphere was analysed by inserting the sample probes at two different depths $(5$ and $10 \mathrm{~cm}$ ) into which the SPME fibre was inserted overnight and then analysed.

Lastly, the whole rose plants without the plastic pot were sampled by placing into $30 \times 35 \times 60 \mathrm{~cm}$ glass chamber was used, the open top was covered with aluminium foil and the fibre inserted into the headspace for 1,2 or $3 \mathrm{~h}$ to record the volatiles emitted from the entire plant.

Blank runs of the fibre and of the two glass chambers and Tedlar bag were run before starting each set of daily sampling. The fibres were removed from the chambers/bags and immediately placed into the injection port of the GC for 5 $\min$ at $250^{\circ} \mathrm{C}$. After analysis, the fibres were thermally desorbed in the GC injector to prevent contamination.

\subsection{Statistical Analyses}

Data were analysed using Statistical Analysis Software (SAS $\left.{ }^{\circledast}\right)$ University edition, and the results were presented by analysis of variance (ANOVA). The areas of ten main peaks were used in analyses. For significant differences, means were compared using Least Significant Difference (LSD) and significant differences are reported at $5 \%$ level of significance.

\section{Results}

\subsection{Selection of Chamber Type and Determination of Extraction Time}

The extraction efficiency of the two different designed chambers $(0.5 \mathrm{~L}$ Tedlar bag and $0.5 \mathrm{~L}$ glass jar) was evaluated by comparing the peak area of the ten compounds from Floribunda and Hybrid Tea roses flowers under the same extraction time, SPME fiber, desorption time, and GC conditions.

There were no significant differences between the glass jar and Tedlar bag, so the jar was chosen because it was easier to use than the Tedlar bag, also the Tedlar bag is not easy to clean as a jar and the Jar is good for capturing the VOCs emitted (Figure 1). Therefore, the jar was selected as appropriate jar to optimize the other parameters.

\subsection{Evaluation of GC Injector (Fiber Desorption) Desorption Time}

The various desorption times $(5,10,15 \mathrm{~min})$ of the three-phase fiber did not differ significantly. Therefore, $5 \mathrm{~min}$ was selected as desorption time (Figure 2).

\subsection{Analysis of Different Extraction Time for Rose Flower}

The three-phase fiber was exposed in the head-space of the jar for three extraction times (1, 2 and $3 \mathrm{~h}$ ), with cut and intact Floribunda and Hybrid Tea flowers under the optimized HS-SPME GC conditions. The total area of VOCs increased 


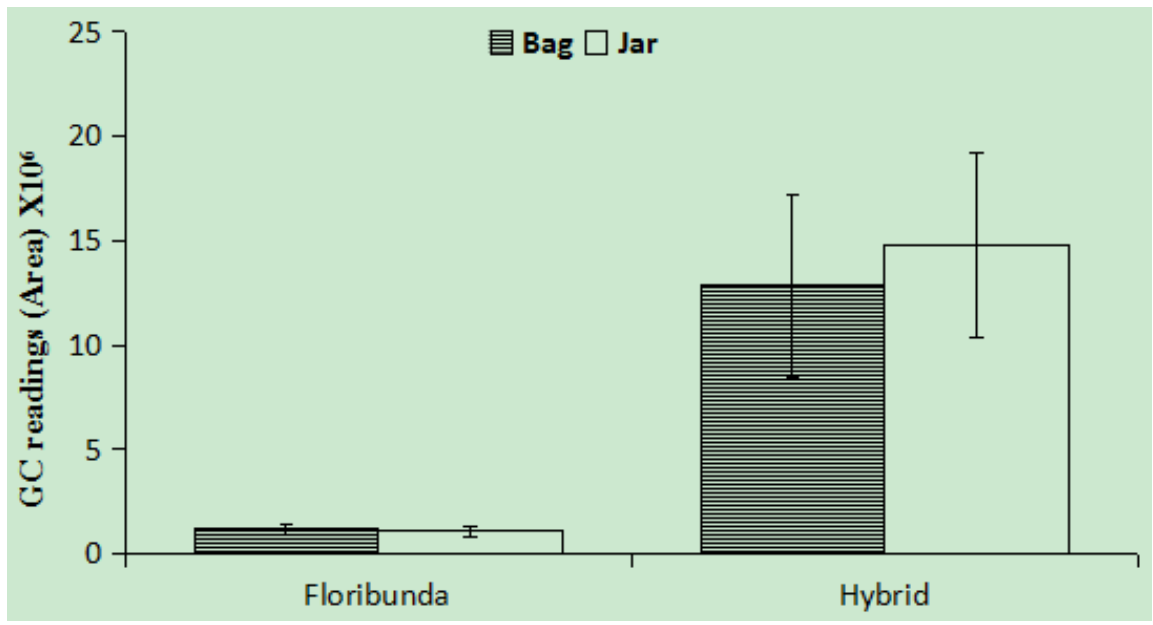

Figure 1. Peaks of volatiles organic compounds (units) produced by intact Floribunda and Hybrid Tea rose flowers extracted by two types of chambers (Tedlar bag and jar). Error bars are LSD at $5 \%(n=3)$.

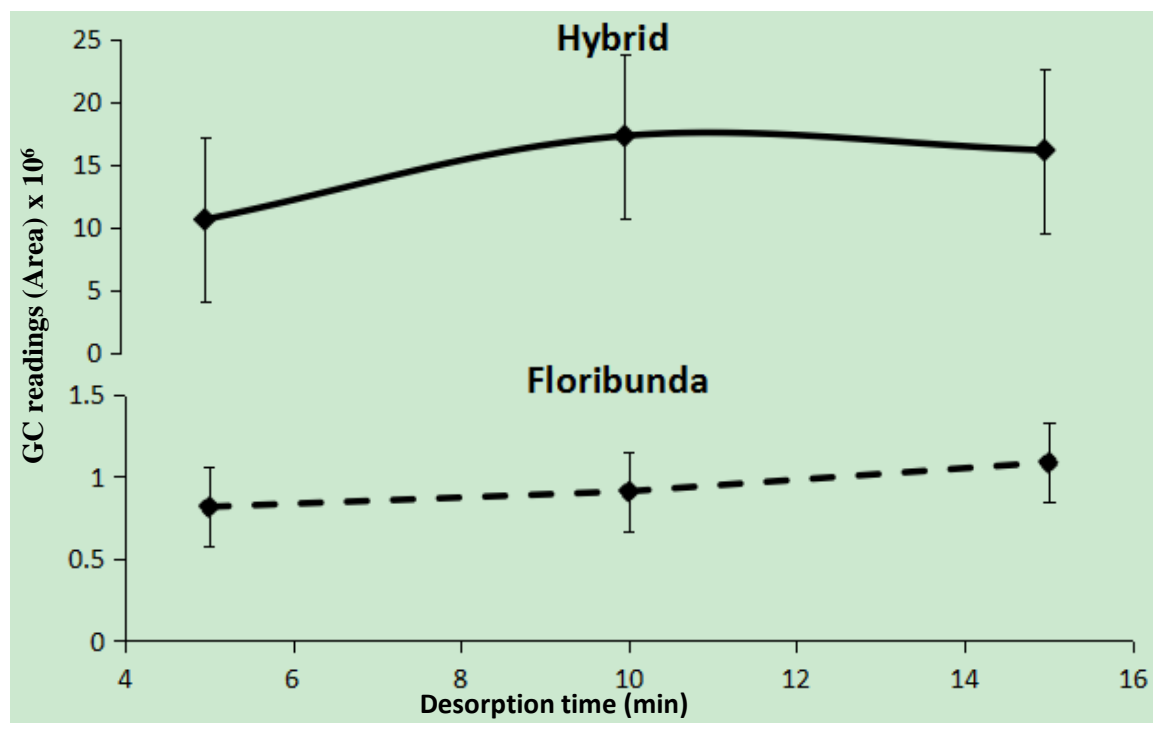

Figure 2. Effects of different desorption times on desorption of VOCs from rose flowers. Bars represent LSD at $5 \%(n=3)$.

from $1 \mathrm{~h}$ to $2 \mathrm{~h}$, but there was no significant difference between 2 and $3 \mathrm{~h}$. Hence the $2 \mathrm{~h}$ extraction time was chosen as the optimum extraction time (Figure 3 ). The differences in GC readings between cut and intact flowers were significant for Floribunda, and the VOCs emitted from the intact flowers were superior to the cut flowers. In contrast, there were no significant differences between the cut and intact flowers for Hybrid Tea. Therefore, intact flowers for both rose cultivars were chosen for further work (Figure 4).

\subsection{Analysis of Different Extraction Time for Rose Leaves}

The optimized HS-SPME and GC conditions were applied to collect the VOCs from cut and intact leaves for both rose cultivars. There were no differences between different extraction times (1,2 and $3 \mathrm{~h}$ ), for both cultivars, so one hour 


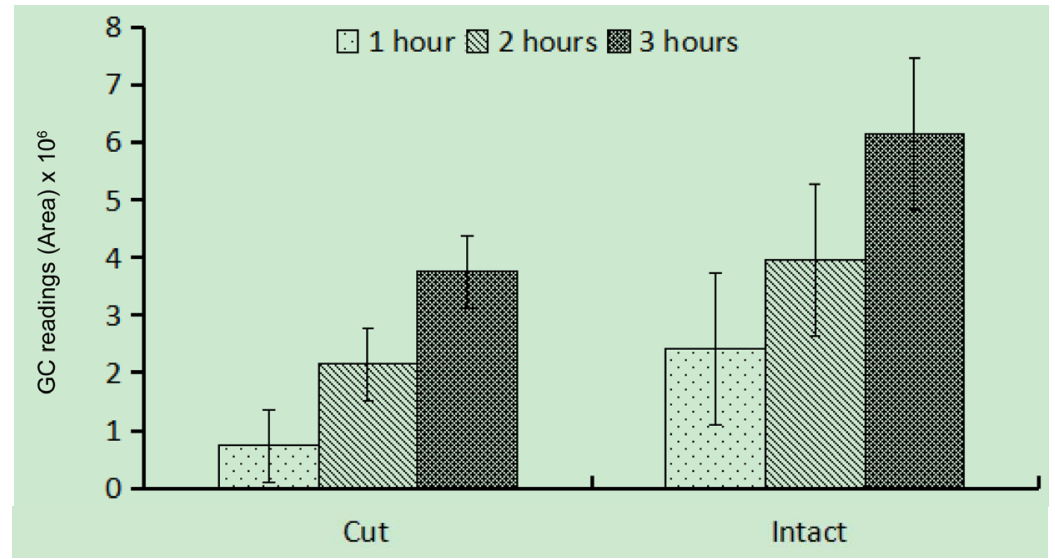

(a)

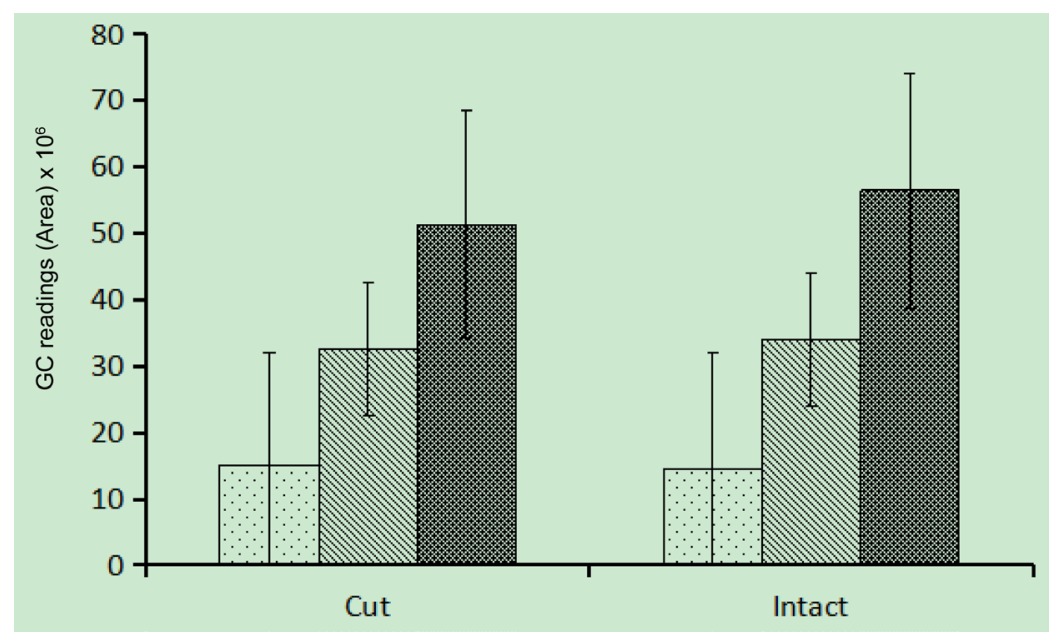

(b)

Figure 3. (a) Effects of extraction time with Floribunda rose (cut and intact) on the extraction efficacy of the total compounds identified from rose flower at 1, 2 and $3 \mathrm{~h}$ for the glass jar; (b) As for (a) for Hybrid Tea rose. Error bars were LSD at 5\% $(n=3)$.

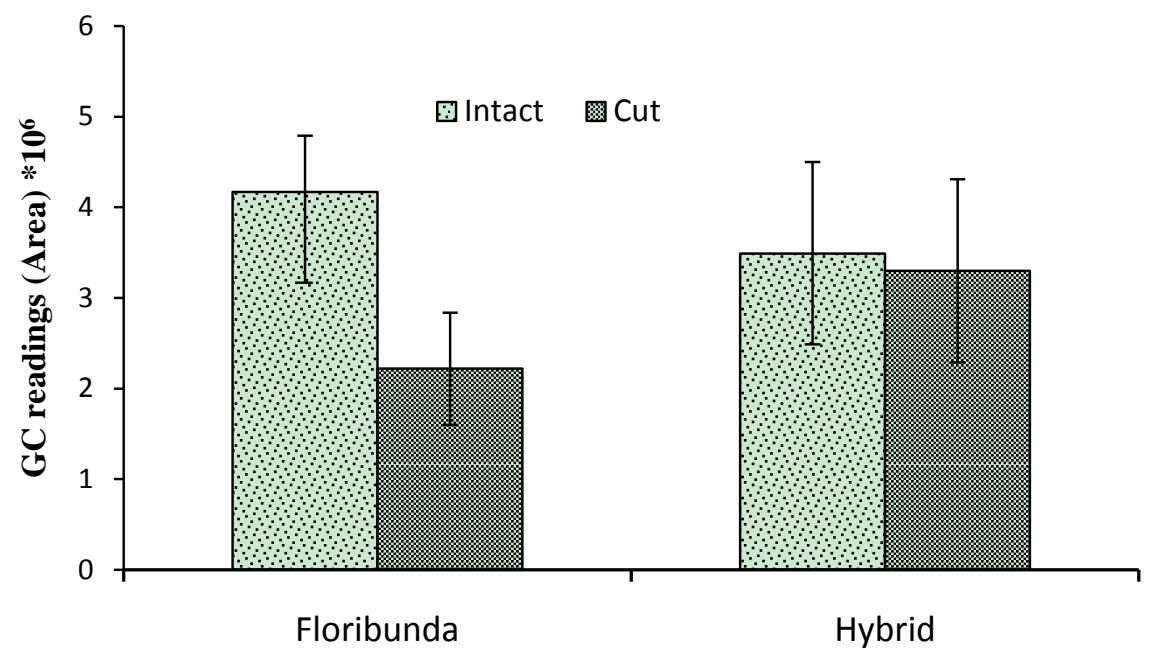

Figure 4. Gas chromatograph readings for volatiles organic compounds emitted from cut and intact rose flowers from floribunda and Hybrid tea rose cultivars. Error bars were LSD at $5 \%(n=3)$. 
was selected (Figure 5). Each cultivar emitted different numbers and amounts of volatiles from the leaves, with larger numbers produced from the intact leaves than the cut leaves for both cultivars (Figure 6).

\subsection{Analysis of Different Extraction Times for Rose Stems}

There were no significant differences in the emission of VOCS from intact and excised rose stems for two rose cultivars. There were ten compounds produced and there were no differences between the different extraction times (1,2 and 3 h) (Figure 7). For the Floribunda cultivar there was no significant difference between cut and intact stems, whilst there were significant differences in the Hybrid Tea cultivar. Overall, the results indicated that cut stems gave superior results compared to intact stems (Figure 8); therefore, cut stems were selected for further studies.

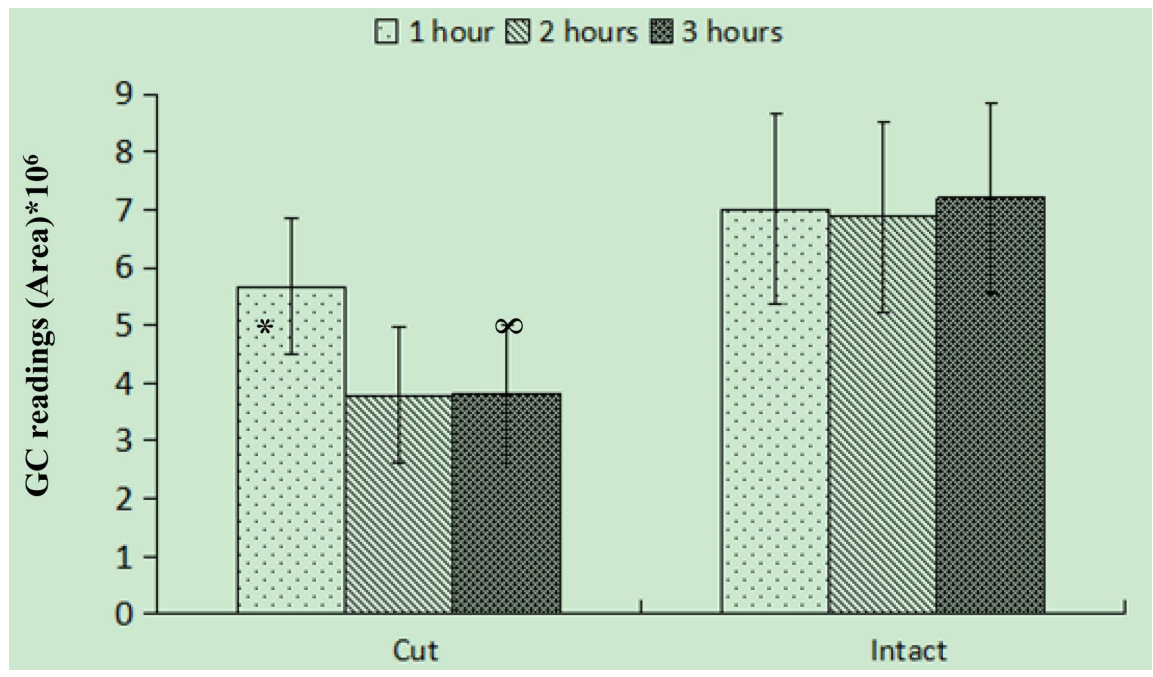

(a)

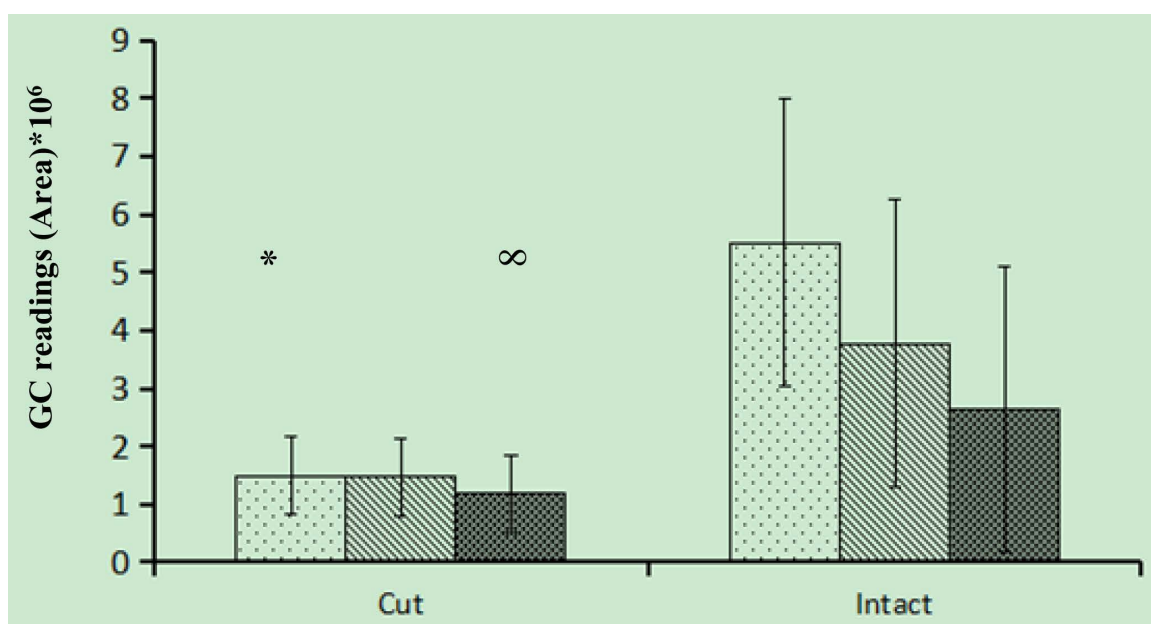

(b)

Figure 5. (a) Volatile organic compounds collected from cut and intact leaves following extraction times of 1, 2 or $3 \mathrm{~h}$ for (a) Floribunda and (b) Hybrid Tea leaves. Error bars were LSD at $5 \%(n=3)$. 


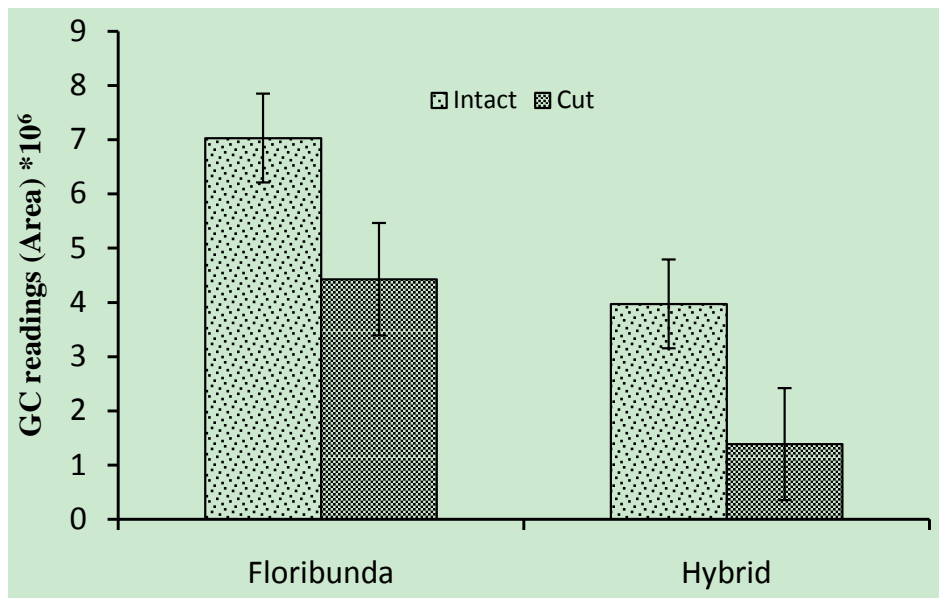

Figure 6. Effect of gas chromatograph reading on emission of volatile organic compounds from cut and intact rose leaves from Floribunda and Hybrid Tea were different. Error bars were LSD at 5\% $(n=3)$.

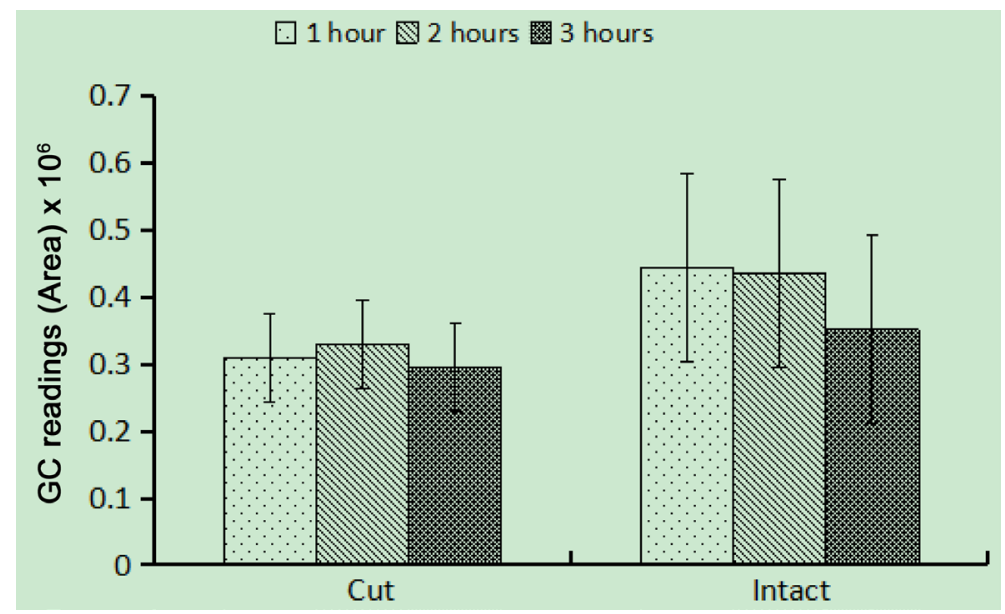

(a)

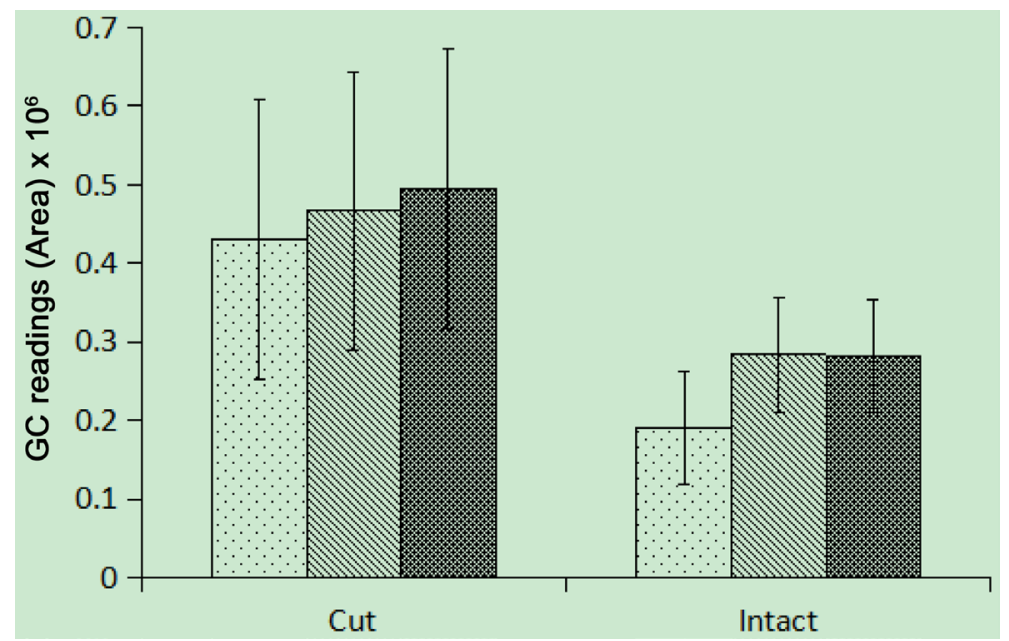

(b)

Figure 7. Volatile organic compounds collected from cut and intact stems following extraction times of 1, 2 or $3 \mathrm{~h}$ for (a) Floribunda and (b), Hybrid Tea leaves. Error bars were LSD at $5 \%(n=3)$. 


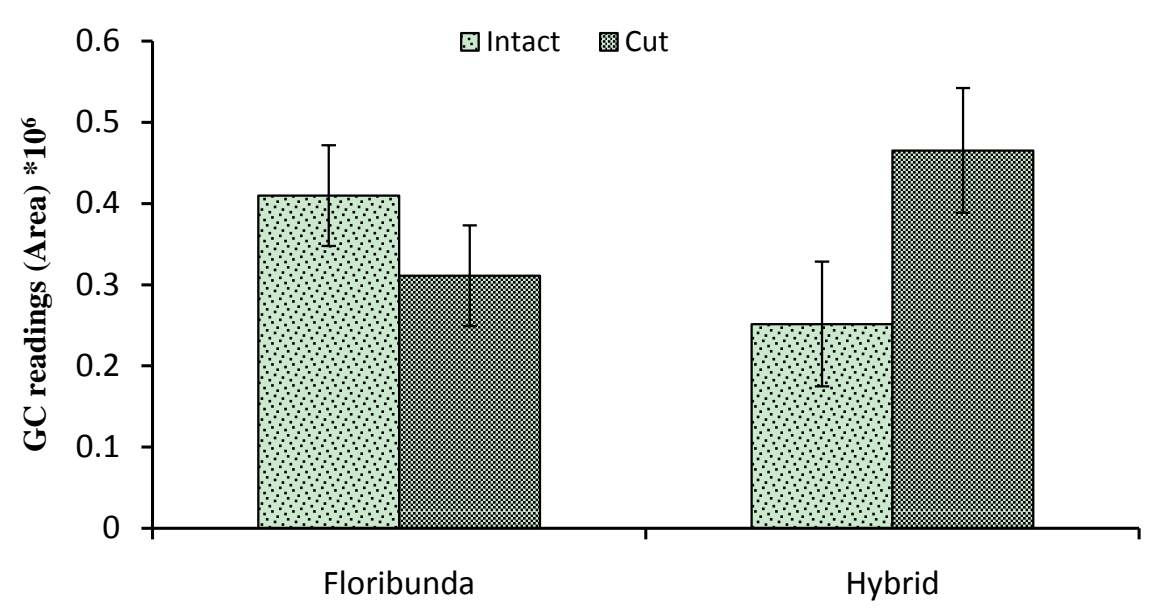

Figure 8. Gas chromatograph readings for volatile organic compounds emitted from cut and intact rose stems from Floribunda and Hybrid Tea rose cultivars. Error bars were LSD at $5 \%(n=3)$.

\subsection{Analysis of Volatiles Organic Compounds in Rose Rhizosphere with Different Extraction Times}

The amount of the volatile compounds did not differ significantly between those collected at $5 \mathrm{~cm}$ than $10 \mathrm{~cm}$ depth (Figure 9). Therefore, the $5 \mathrm{~cm}$ was selected for subsequent studies. The VOCs emitted from Floribunda rhizosphere did not differ significantly between the different extraction times $(6,12,16 \mathrm{~h})$. Therefore, six hours was chosen for farther subsequent studies for Floribunda (Figure 10). In contrast, in Hybrid Tea there were significantly differences in the amounts of VOCs produced at the different extraction times from the rhizosphere (Figure 10). Therefore, $12 \mathrm{~h}$ was selected for best extraction time to absorb the VOCs emitted from rhizosphere of Hybrid Tea cultivar.

\subsection{Analysis of Different Extraction Time for Whole Rose Plants}

The three-phase fiber was exposed to a whole rose plant in a glass chamber for three extraction times (1, 2 and $3 \mathrm{~h}$ ). There were no differences for the total area of VOCs for Floribunda and Hybrid Tea rose cultivars (Figure 11) with the extraction time. A Therefore, one-hour extraction time is suitable for the subsequent studies.

\section{Discussion}

This study was analyzed different rose tissues with different chambers types for extracted VOCs from two rose cultivars. There were no significant differences between the Tedlar bag and Pyrex glass jar as chambers to capture VOCs. However, since the glass jar proved to be an easy to handle and clean, and a reliable way to collect VOC extracts from intact or excised rose organs, which agrees with the study by [24] who used an SPME fiber to extract a number of high quality VOCs from Jasminum.

Desorption time is an important process and it depends on speed of desorption of the VOCs from the fiber through the injection port. Theoretically, 


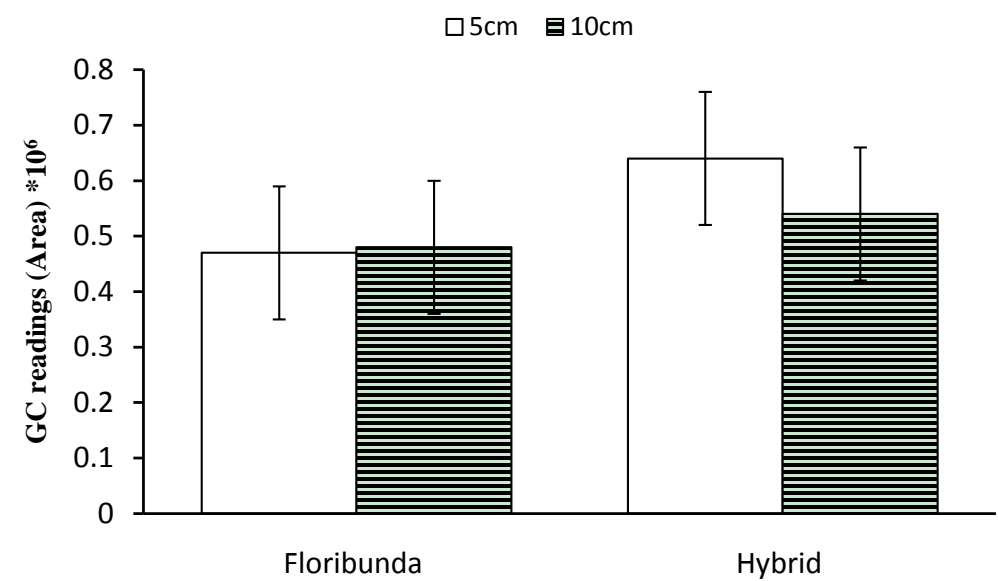

Figure 9. Effects of soil depth (5 and $10 \mathrm{~cm}$ ) on desorption of volatile organic compounds of Floribunda and Hybrid Tea rose cultivars. Bars represent LSD at 5\% $(n=3)$.

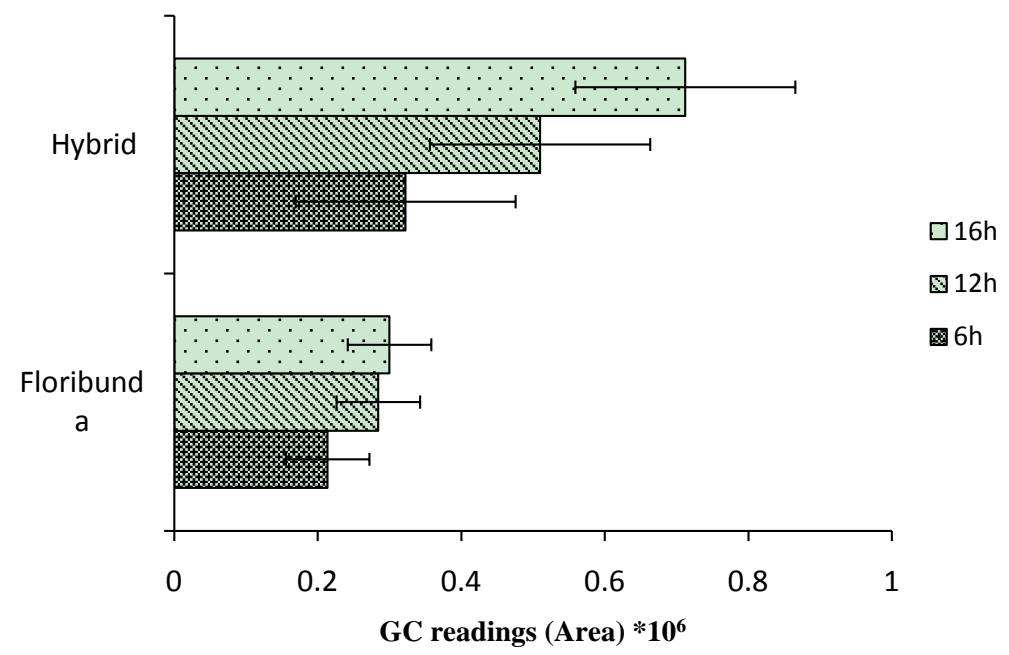

Figure 10. Effects of extraction time with Floribunda and Hybrid Tea rose cultivars on the extraction efficacy of the total compounds identified from the rhizosphere at 6,12 and 16 h. Error bars were LSD at $5 \%(n=3)$.

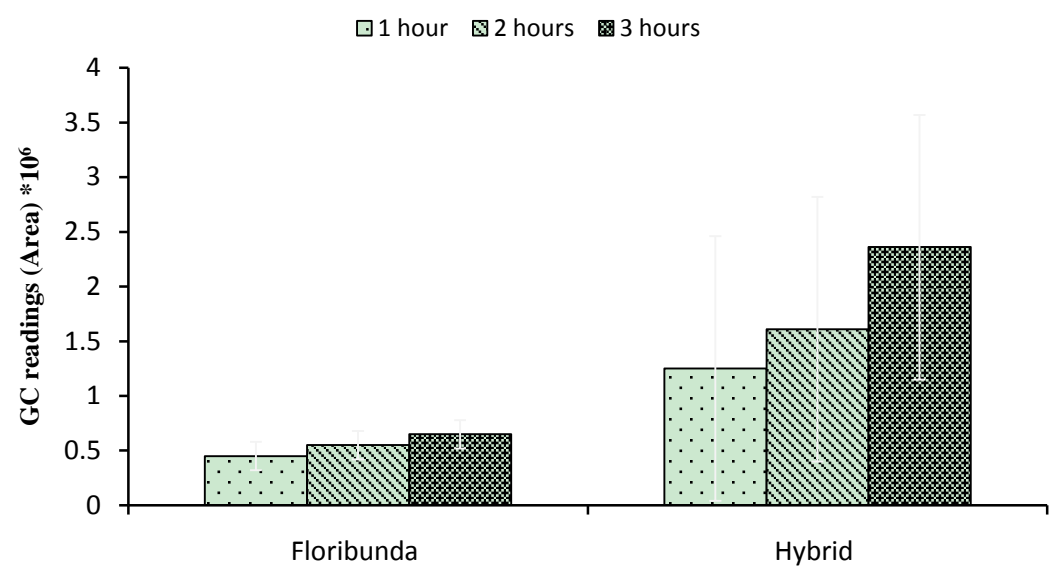

Figure 11. Volatile organic compounds collected from whole rose plants following extraction times of 1, 2 or $3 \mathrm{~h}$ for Floribunda and Hybrid Tea rose cultivars. Error bars were LSD at $5 \%(n=3)$. 
desorption time should be appropriate enough to completely release all the absorbed volatiles from the fiber. This is because the optimum desorption was used at $250^{\circ} \mathrm{C}$; this temperature was selected for the whole experiment. In fact, there are two factors that should be considered: (1) in the SPME technique, injection port temperature is important because every fiber has a temperature stability range based on the fiber coating (e.g. for the three-phase fiber, $270^{\circ} \mathrm{C}$ is recommended as the limit of temperature tolerance), and (2) exposure of the fiber to very high temperatures can shorten the fiber's life a result in the loss of the fiber's polymer coating [32]. Moreover, high temperatures used for the release of the VOCs from the fiber in the injection port can reduce GC sensitivity; this could be due denaturation, destruction, or decomposition of the chemicals at higher temperature [33]. Therefore, there is a need to optimize the temperatures used to ensure maximum release of VOCs from the fiber without compromising the composition of VOCs released.

In this study, optimal extraction time from the fiber for both intact and excised flowers was $2 \mathrm{~h}$, which is longer than the time used by [24] who reported $15 \mathrm{~min}$ as the optimum extraction time to extract the volatiles compounds produced by Jasminum sambac flower. This difference is most likely due to the different plant species being tested, since, the extraction time depends on the chemical nature of the compounds present, the distribution constant, the fiber polymeric phase, and to the size of the molecular mass (e.g., polyunsaturated fatty acids and other compounds are expected to require longer extraction times depending on their lower partitioning and diffusion coefficient). The HS-SPME method has been used for extracting volatile compounds from flowers at room temperature, this method is favorable for flower VOCs analysis, because it minimizes high temperature artifacts [34]. In the present study, the results indicated that there were differences between intact and cut flower for the Floribunda cultivar, and intact flowers were superior to excised flower by total peak area. In contrast, there were no differences between excised and intact flowers for the Hybrid Tea cultivar. Apparently, more volatiles are emitted from the Hybrid Tea cultivar than Floribunda cultivar (Figure 12), and this is because different species have different types and amounts of compounds. Furthermore, Chinese roses and European roses including the hybrid tea have higher scent than the other rose types [3] [12] [35] [36].

In general, all plants have the ability to emit VOCs and the content and composition of these VOCs will depend on the plant species and plant organ. The VOCs emitted from plant leaves are considered the main challenges in plant VOCs research because they are difficult to sample accurately due to the low concentrations of VOCs present and the inherent reactivity of some VOC compounds that makes them hard to detect directly [37]. Using the optimized HS-SPME method developed in this study we were able to accurately detect volatiles from excised and intact rose leaves, and there were no significant differences between different extraction times, and a $1 \mathrm{~h}$ extraction time was chosen for both cultivars. In contrast, [38] using an SPME fiber with glass chamber used 


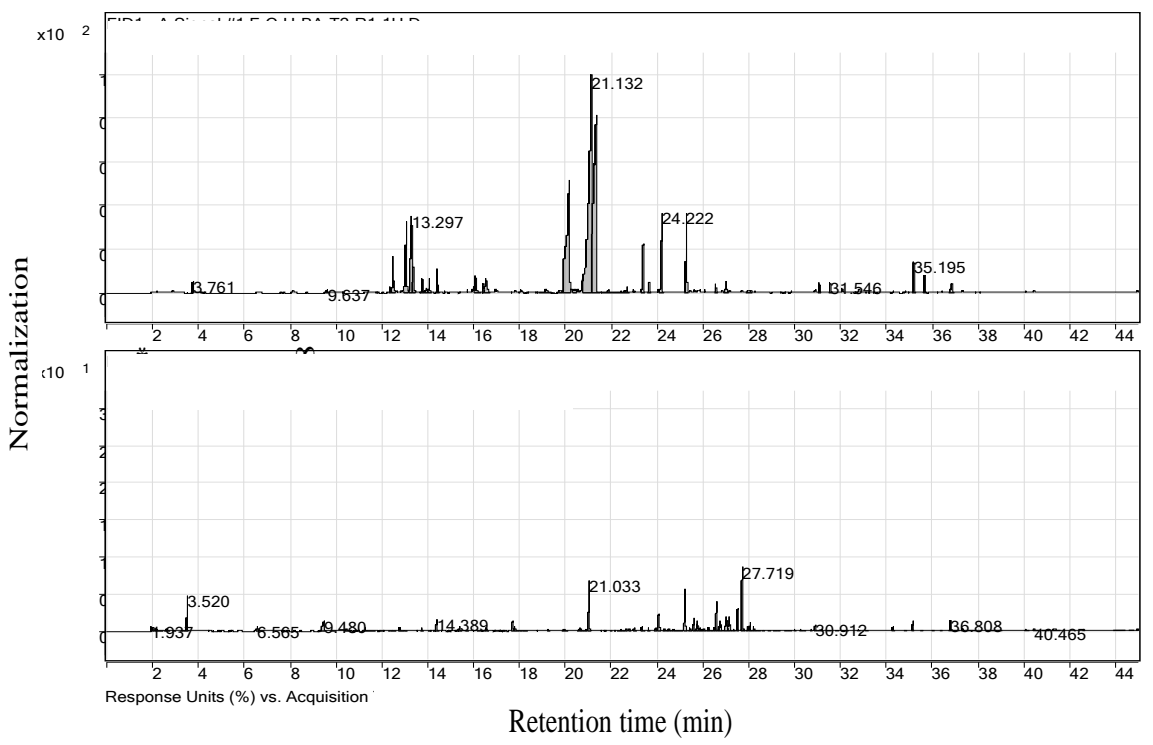

Figure 12. Gas chromatography (GC) chromatograms of (a) Hybrid Tea rose and (b) Floribunda rose.

an extraction time of 1 min performed every 30 min to identify VOCs from intact Eucalyptus leaves. Moreover, [37] reviewed that VOCs from foliage can be analyzed using different sampling methods and available analytical techniques used for this purpose. Also, they indicated these methods will allow biologists moving into the field to analyze their studies on VOCs. In the present study, we found significant differences between cut and intact leaves for the two cultivars, with more VOCs obtained from attached rose leaves for both cultivars. This may be because for the intact leaves, respiration and photosynthesis are higher than the cut leaves, and consequently more plant secondary metabolites are produced. To our knowledge, this is the first comprehensive study on the VOCs of cut and intact rose leaves.

Using the optimized HP-SPME fiber method developed in this study, we found that the GC chromatogram for different extraction times were not different between intact or excised rose stems for both rose cultivars and a $1 \mathrm{~h}$ extraction was effective. A recent study on Thymus stems indicated that VOCs extracted using hydro distillation and solvent microwave extraction techniques were higher than from root volatiles [39]. Likewise, a study by [40] found VOCs emitted from Polygnum minus stems, were more effectively detected on and SPME fiber after the stems were ground to a powder and the VOCs extracted with hydro distillation. Most of the volatiles that were detected from the intact and cut Floribunda stems indicated that there were no differences between cut and intact Floribunda stem. In contrast, there were significant differences between the intact and cut Hybrid Tea stems, with more VOCs obtained from intact stems than cut stems.

The results clearly show that the HS-SPME combined with GC-FID can be reliably used to analyze VOCs from the rhizophere of rose plants, and that depth of extraction did not effect on total peak area. This may be because the VOCs 
have small molecular weight and are readily move into the extraction tube inserted into the soil. There were no significant differences in extraction times for the Floribunda cultivar, and a $6 \mathrm{~h}$ extraction was selected. In contrast, for the Hybrid Tea cultivar a $12 \mathrm{~h}$ extraction time was chosen as there were significant differences between the different extraction times. The $12 \mathrm{~h}$ extraction time was chosen because VOCs emissions from rhizosphere are affected by a variety of factors such as temperature, moisture and differences between species. Also extraction time depends on the distribution constant, chemical nature of desired compounds, and fiber polymeric phase. Most of the volatiles detected from whole rose plant indicated there were no significant differences between different extraction times for both rose cultivars; consequently $1 \mathrm{~h}$ was considered an optimal extraction time for whole plants.

The HS-SPME fiber technique is simple and can be readily used both in the laboratory and on-site [41]. HS-SPME can reduce the time used for extraction significantly because of the faster diffusion rate of the molecules in the gaseous phase. Furthermore, the fiber is suspended in the HS above the sample, so there is no contamination of the fiber by the sample. From our study, the fibers can be reused more than 200 times before they deteriorate, therefore reducing the cost of the materials. Finally, HS-SPME GC does not require skilled technicians as it can be readily and reliably used after a short period of training.

To our knowledge, this is the first study on use of VOCs from different organs of rose cultivars, and it is the first time the HP-SPME technique has been used to identify VOCs from attached and excised flowers, leaves, stems, roots and soil (rhizosphere), and the whole plant for roses. The HS-SPME technique coupled with GC is a robust and cost effective system for the identification of rose volatiles. Further studies are in progress to detect and identify the VOCs that are released from different rose organs by GC-MS. Therefore; the optimized methods developed in this study can be used either as a detection tool or as a new qualitative methodology for physiological studies of roses and other horticultural include horticulture plants and agricultural plants.

\section{Conclusion}

This study concluded that glass jar with 5 min desorption time showed a good result for extract VOCs from rose. Different rose tissues showed different ability for extraction time, where $2 \mathrm{~h}$ extraction time was good for extract VOCs from flower tissue for both rose cultivars. However, the result indicated that $1 \mathrm{~h} \mathrm{ex}-$ tract time for leaves, stems and whole rose plant gave a good result for both rose cultivars. On the other hand, there was a difference between the two rose cultivars in ability of extraction time VOCs from rhizosphere. The result indicated that $6 \mathrm{~h}$ extraction time was good for Floribunda cultivar, while $12 \mathrm{~h}$ was good for Hybrid Tea cultivar.

\section{Acknowledgements}

We thank the Iraqi Government via the Higher Committee for Education De- 
velopment (HCED) for scholarship to the senior author. We also thank James Newman from Murdoch University to help us with experiment tools, and Bob Du with lab instruments. Also we would like to thank Melville nursery for information about rose cuttings and Charles Obiero for helping us in statistical analysis.

\section{References}

[1] Gudin, S. (2000) Rose: Genetics and Breeding. In: Janick, J., Ed., Plant Breeding Reviews, John Wiley \& Sons, Inc., New York, 159-189.

[2] Weiss, E.A. (1997) Rosaceae. In: Essential Oil Crops, CAB International Wallingford, Oxon, UK, 393-416.

[3] Guterman, I., Dafny-Yelin, M., Shalit, M., Emanuel, M., Shaham, N., Piestun, D., Zuker, A., Ovadis, M., Lavi, M. and Lavid, N. (2002) An Integrated Genomic Approach to Discovering Fragrance-related Genes in Rose Petals. Flowering Newsletter, 32, 31-37.

[4] Kovacheva, N., Rusanov, K. and Atanassov, L. (2010) Industrial Cultivation of Oil Bearing Rose and Rose Oil Production in Bulgaria during the 21st Century, Directions and Challenges. Biotechnology \& Biotechnological Equipment, 24, 1793-1798. https://doi.org/10.2478/V10133-010-0032-4

[5] Department of Foreign Affairs and Trade (2016) Services Trade Access Requirements Database. Australian Bureau of Statistics; Catalogue Number 5368.0.

[6] Özel, M.Z., Gogus, F. and Lewis, A.C. (2006) Comparison of Direct Thermal Desorption with Water Distillation and Superheated Water Extraction for the Analysis of Volatile Components of Rosa damascena Mill. Using GCxGC-TOF/MS. Analytica Chimica Acta, 556, 172-177. https://doi.org/10.1016/j.aca.2006.03.014

[7] Rusanov, K., Kovacheva, N., Rusanova, M. and Atanassov, L. (2011a) Traditional Rosa damascena Flower Harvesting Practices Evaluated through GC/MS Metabolite Profiling of Flower Volatiles. Food Chemistry, 129, 1851-1859.

https://doi.org/10.1016/j.foodchem.2011.05.132

[8] Baydar, H. and Baydar, G.N. (2005) The Effects of Harvest Date, Fermentation Duration and Tween 20 Treatment on Essential Oil Content and Composition of Industrial Oil Rose (Rosa damascena Mill.). Industrial Crops and Products, 21, 251255. https://doi.org/10.1016/j.indcrop.2004.04.004

[9] Rusanov, K., Kovacheva, N. and Atanassov, L. (2011b) Comparative GC/MS Analysis of Rose Flower and Distilled Oil Volatiles of the Oil Bearing Rose Rosa damascena. Biotechnology \& Biotechnological Equipment, 25, 2210-2216. https://doi.org/10.5504/BBEQ.2011.0015

[10] Pellati, F., Orlandini, G., Leeuwen, K.A., Anesin, G., Bertelli, D., Paolini, M., Benvenuti, S. and Camin, F. (2013) Gas Chromatography Combined with Mass Spectrometry, Flame Ionization Detection and Elemental Analyzer/Isotope Ratio Mass Spectrometry for Characterizing and Detecting the Authenticity of Commercial Essential Oils of Rosa damascena Mill. Rapid Communications in Mass Spectrometry, 27, 591-602. https://doi.org/10.1002/rcm.6489

[11] Scalliet, G., Piola, F., Douady, C.J., Réty, S., Raymond, O., Baudino, S., Bordji, K., Bendahmane, M., Dumas, C., Cock, J.M. and Hugueney, P. (2008) Scent Evolution in Chinese Roses. Proceedings of the National Academy of Sciences, 105, 59275932. https://doi.org/10.1073/pnas.0711551105

[12] Joichi, A., Yomogida, K., Awano, K.I. and Ueda, Y. (2005) Volatile Components of 
Tea-Scented Modern Roses and Ancient Chinese Roses. Flavour and Fragrance Journal, 20, 152-157. https://doi.org/10.1002/ffj.1388

[13] Myers, M. (2013) Midwest Gardener's Handbook: Your Complete Guide: Select Plan - Plant - Maintain - Problem-Solve - Illinois, Indiana, Iowa, Kansas, Michigan, ... North Dakota, Ohio, South Dakota, Wisconsin. 19-154.

[14] Kigathi, R.N., Unsicker, S.B., Reichelt, M., Kesselmeier, J., Gershenzon, J. and Weisser, W.W. (2009) Emission of Volatile Organic Compounds after Herbivory from Trifolium pratense (L.) under Laboratory and Field Conditions. Journal of Chemical Ecology, 35, 1335-1348. https://doi.org/10.1007/s10886-009-9716-3

[15] Hosni, K., Kerkenni, A., Medfei, W., Brahim, N.B. and Sebei, H. (2010) Volatile Oil Constituents of Rosa Canina L.: Quality as Affected by the Distillation Method. Organic Chemistry International, 1-7.

[16] Naquvi, K.J., Ansari, S.H., Ali, M. and Najmi, K. (2014) Volatile Oil Composition of Rosa damascena Mill (Rosaceae). Journal of Pharmacognosy and Phytochemistry, 2, 177-181.

[17] Dobreva, A. (2013) Dynamics of the Headspace Chemical Components of Rosa damascena Mill. Flowers. Journal of Essential Oil Bearing Plants, 16, 404-411. https://doi.org/10.1080/0972060X.2013.813229

[18] Deng, C., Xu, X., Yao, N., Li, N. and Zhang, X. (2006) Rapid Determination of Essential Oil Compounds in Artemisia Selengensis Turcz by Gas ChromatographyMass Spectrometry with Microwave Distillation and Simultaneous Solid-phase Microextraction. Analytica Chimica Acta, 556, 289-294. https://doi.org/10.1016/j.aca.2005.09.038

[19] Sparinska, A. and Rostoks, N. (2015) Volatile Organic Compounds of Hybrid Rugosa Roses in Latvia. Proceedings of the Latvian Academy of Sciences, Section B, Nat Exact Appl Sci., 69, 57-61.

[20] Koksal, N., Saribas, R., Kafkas, E., Aslancan, H. and Sadighazadi, S. (2015) Determination of Volatile Compounds of the First Rose Oil and the First Rose Water by HSSPME/GC/MS Techniques. African Journal of Traditional, Complementary and Alternative Medicines, 12, 145-150. https://doi.org/10.4314/ajtcam.v12i4.21

[21] Kiralan, M. (2015) Use of Headspace Solid-phase Microextraction in Rose (Rosa damascena Mill.) Products for Volatile Compounds. Journal of Essential Oil Bearing Plants, 18, 1266-1270. https://doi.org/10.1080/0972060X.2015.1044571

[22] Zhu, S., Yang, Y., Yu, H., Ying, Y. and Zou, G. (2005) Chemical Composition and Antimicrobial Activity of the Essential Oils of Chrysanthemum indicum. Journal of Ethnopharmacology, 96, 151-158. https://doi.org/10.1016/j.jep.2004.08.031

[23] Chang, K.M. and Kim, G.H. (2008) Volatile Aroma Composition of Chrysanthemum indicum L. Flower Oil. Journal of Food Science and Nutrition, 13, 122-127.

[24] Pragadheesh, V.S., Yadav, A., Chanotiya, C.S., Rout, P.K. and Uniyal, G.C. (2011) Monitoring the Emission of Volatile Organic Compounds from Flowers of Jasminum sambac Using Solid-phase Micro-extraction Fibers and Gas Chromatography with Mass Spectrometry Detection. Natural Product Communications, 6, 1333 1338.

[25] Prosen, H. and Zupančič, K.L. (1999) Solid-phase Microextraction. TrAC Trends in Analytical Chemistry, 18, 272-282. https://doi.org/10.1016/S0165-9936(98)00109-5

[26] Bicchi, C., Drigo, S. and Rubiolo, P. (2000) Influence of Fibre Coating in Headspace Solid-phase Microextraction Gas Chromatographic Analysis of Aromatic and $\mathrm{Me}$ dicinal Plants. Journal of Chromatography A, 892, 469-485. https://doi.org/10.1016/S0021-9673(00)00231-4 
[27] Wardencki, W., Michulec, M. and Curylo, J. (2004) A Review of Theoretical and Practical Aspects of Solid-phase Microextraction in Food Analysis. International Journal of Food Science and Technology, 39, 703-717. https://doi.org/10.1111/j.1365-2621.2004.00839.x

[28] Dorea, H.S., Gaujac, A. and Navickien, S. (2008) Solid-Phase Microextraction: Thermodynamic and Kinetic Aspects. Scientia Plena, 4, 1-7.

[29] Jelen, H.H., Majcher, M. and Dziadas, M. (2012) Microextraction Techniques in the Analysis of Food Flavor Compounds: A Review. Analytica Chimica Acta, 738, 13 26. https://doi.org/10.1016/j.aca.2012.06.006

[30] Nongonierma, A., Cayot, P., Quere, J.L., Springett, M. and Voilley, A. (2006) Mechanisms of Extraction of Aroma Compounds From Foods, Using Adsorbents. Effect of Various Parameters. Food Reviews International, 22, 51-94. https://doi.org/10.1080/87559120500379951

[31] Ferreira, S.L., Bruns, R.E., Ferreira, H.S., Matos, G.D., David, J.M., Brandao, G.C., da Silva, E.G., Portugal, L.A., dos Reis, P,S., Souza, A.S. and dos Santos, W.N. (2007) Box-Behnken Design: An Alternative for the Optimization of Analytical Methods. Analytica Chimica Acta, 597, 179-186. https://doi.org/10.1016/j.aca.2007.07.011

[32] Qiu, R., Dong, Q., Giles, H., Robert, T., Manjree, A. and Yonglin, R. (2014) Optimization of Headspace Solid-phase Microextraction Conditions for the Identification of Phytophthora cinnamomi Rands. Plant Disease, 18, 1088-1098. https://doi.org/10.1094/PDIS-12-13-1258-RE

[33] Magan, N. and Evans, P. (2000) Volatiles as An Indicator of Fungal Activity and Differentiation Between Species, and the Potential Use of Electronic Nose Technology for Early Detection of Grain Spoilage. Journal of Stored Products Research, 36, 319-340. https://doi.org/10.1016/S0022-474X(99)00057-0

[34] Chen, H.C., Chi, H.S. and Lin, L.Y. (2013) Headspace Solid-phase Microextraction Analysis of Volatile Components in Narcissus tazetta var. Chinensis Roem. Molecules, 18, 13723-13734. https://doi.org/10.3390/molecules181113723

[35] Flament, I., Debonneville, C. and Furrer, A. (1993) Volatile Constituents of Roses: Characterization of cultivars based on the headspace analysis of living flower emissions. In: Teranishi, R., Buttery, R.G. and Sugisawa, H., Eds., Bioactive Volatile Compounds from Plants, American Chemical Society, Washington DC, 269-281. https://doi.org/10.1021/bk-1993-0525.ch019

[36] Nakamura, S. (1987) Scent and Component Analysis of the Hybrid Tea Rose. Perfumer and Flavorist, 12, 43-45.

[37] Materic, D., Dan, B., Claire, T., Geraint, M., Nigel, M. and Vincent, G. (2015) Methods in Plant Foliar Volatile Organic Compounds Research. Applications in Plant Sciences, 3, 1-10. https://doi.org/10.3732/apps.1500044

[38] Zini, C.A., Augusto, F., Christensen, E., Caramao, E.B. and Pawliszyn, J. (2002) SPME Applied to the Study of Volatile Organic Compounds Emitted by Three Species of Eucalyptus in Situ. Journal of Agricultural and Food Chemistry, 50, 71997205. https://doi.org/10.1021/jf025666m

[39] Azar, P.A., Zahra, A.M., Mohammed, S.T. and Kambiz, L. (2011) Composition of Essential Oil of Leaves Stems and Roots by Different Extraction Methods of Thymus kotschyanus Boiss. \& Hohen var. Pseuderiophorus Rech. f.p.p. Grown Wild in Iran. Asian Journal of Chemistry, 23, 4271-4275.

[40] Ahmad, R., Syarul, N.B., Hamidun, B., Minki, L., Normah, M.N., Emelda, R.R., Norashikin, L. and Noraziah, M.Z. (2014) Volatile Profiling of Aromatic Traditional Medicinal Plant Polygonum minus in Different Tissues and Its Biological Activities. Molecules, 19, 19220-19242. https://doi.org/10.3390/molecules191119220 
[41] Zhu, J.Y. and Chai, X.S. (2005) Some Recent Developments in Headspace Gas Chromatography. Current Analytical Chemistry, 1, 79-83.

https://doi.org/10.2174/1573411052948488

\section{Scientific Research Publishing}

Submit or recommend next manuscript to SCIRP and we will provide best service for you:

Accepting pre-submission inquiries through Email, Facebook, LinkedIn, Twitter, etc. A wide selection of journals (inclusive of 9 subjects, more than 200 journals)

Providing 24-hour high-quality service

User-friendly online submission system

Fair and swift peer-review system

Efficient typesetting and proofreading procedure

Display of the result of downloads and visits, as well as the number of cited articles Maximum dissemination of your research work

Submit your manuscript at: http://papersubmission.scirp.org/

Or contact jbm@scirp.org 